(C) 2016, Elsevier. Licensed under the Creative Commons Attribution-NonCommercial-NoDerivatives 4.0 International

http://creativecommons.org/licenses/by-nc-nd/4.0/

\title{
The Use of Modelling in Purchasing/Supply Management Research
}

\begin{abstract}
The purpose of this research to explore the use of modelling in the field of Purchasing and Supply Management (P/SM). We are particularly interested in identifying the specific areas of P/SM where there are opportunities for the use of modelling based methods. The paper starts with an overview of main types of modelling and also provides a categorization of the main $\mathrm{P} / \mathrm{SM}$ research themes. Our research shows that there are many opportunities for using descriptive, predictive and prescriptive modelling approaches in all areas of P/SM research from the ones with a focus on the actual function from a purely operational and execution perspective (e.g. purchasing processes and behaviour) to the ones with a focus on the organisational level from a more strategic perspective (e.g. strategy and policy). We conclude that future P/SM research needs to explore the value of modelling not just at the functional or operational level, but also at the organisation and strategic level respectively. We also acknowledge that while using empirical results to inform and improve models has advantages, there are also drawbacks, which relate to the value, the practical relevance and the generalizability of the modelling based approaches.
\end{abstract}

Keywords: Purchasing and Supply Management, Modelling, Multi-method research.

\section{What is modelling and what are the generic types of modelling?}

Modelling is a simplified and usually mathematical representation of a process or a system to support decision-making or to simply understand the actual situation better. In terms of the purpose of the modelling exercise, models can be categorised into three types: descriptive, predictive, and prescriptive.

Descriptive models provide insight into the past including what happened, and more usefully, why it might have happened. Such models usually constitute a base-case that can be used as a benchmark to make and test suggested improvements.

Predictive models are aimed at understanding the future including what could happen given what we know about a system. Regression is one of the well-known predictive models along with time series forecasting models that are used to predict the future behaviour of a variable of interest. These predictive models represent what could happen in the future, rather than what should be done to reach a desirable outcome, which is addressed by prescriptive models.

Optimisation models (e.g. linear programming, integer programming, multi-objective mathematical programming) prescribe the decision maker the best course of action in order to achieve the set objective (e.g. profit / welfare maximisation, cost / time minimisation). Such 
models are comprised of mainly three building blocks: objective function(s), decision variables, and constraints.

Simulation models can be used for descriptive, predictive and prescriptive purposes. They are very useful in understanding the current situation of a system, and they are also a costeffective way of experimenting with multiple designs and the variation that can occur in a system.

In terms of the input data and model parameters, it is possible to develop either deterministic or probabilistic models. Deterministic models assume that the parameter values are known with certainty, whereas probabilistic models may incorporate stochastic properties in the parameters and decision variables. Both deterministic models and probabilistic models have proven to be quite useful since the start of the management science discipline; however, choosing the appropriate type of model could also be a modelling exercise.

\section{Why do we need models?}

The problems faced in both the public and private sector are quite complex, necessitating rigorous and representative models. Models are often needed to understand a system, to predict the behaviour of a system, or to identify points of intervention in order to change a system in the desired direction. Most often, it is impossible to arrive at a desired system status by trial and error. It is not only costly but simply impractical to make an arbitrary decision and then assess whether or not is was the right decision. Therefore, models are needed to accurately formulate a problem and to develop meaningful solutions to that problem. In the formulation of the problem, a critical aspect of the model building is the parameterisation of the model.

However, models that are not based on practical observation may lack explanatory power. Therefore, empirical data are required to determine the values of the parameters in a decision model. A model takes its power from the representation of the real situation and therefore relies on various methods of empirical data collection and analysis. There are a plethora of models that can be applied in the purchasing/supply management domain, ranging from models for strategic decisions such as supplier network design and outsourcing strategy to models for tactical decisions such as capacity planning or operational decisions such as a contract negotiation or e-procurement. Modelling is a versatile tool applicable to many supply management problems, and its sole purpose is to help make better decisions for the firm and the related supply chain.

\section{The P/SM Discipline: key themes/research areas}


The academic disciplines of supply chain management (SCM) and purchasing and supply management (PSM) have grown significantly in the last twenty years, and this is reflected not only in the number of journals covering these fields but also in the growth of the respective professional bodies (e.g. CIPS, ISM, CSCMP). Despite the fact that academia is not always closely aligned with industry and practitioners, it could be argued that in SCM, particularly from a PSM perspective, there are seven main key themes (and sub-themes) in research and practice that keep academics' and practitioners' attention. They include: Supplier Relationship Management (e.g. Supplier Development, Supplier Co-ordination / Association), Developing and Managing Contracts (e.g. Negotiation, Contract Management, Conflict Resolution), Purchasing Processes and Behaviour (e.g. Needs Assessment / Commissioning, Data Analysis / Business Intelligence, Supplier Evaluation and Appraisal, Sourcing and Tendering), People and Skills in the Purchasing and Supply Organisation (e.g. Leadership and Promotion of Procurement and Supply Management, Change Management, Purchasing and Supply Team Governance), Strategy and Policy (e.g. Category Management, Make-or-Buy / Outsourcing Strategy, Procurement Policy Development), ICT (e.g. e-Sourcing / e-Procurement Systems, e-Auctions / Reverse Auctions) and Risk / Mitigation (e.g. Counterfeit, Fraud and Transparency, Risk Analysis and Management).

Some of these seven themes (e.g. purchasing processes and behaviour) focus more on the actual function from a purely operational and execution perspective, while others (e.g. strategy and policy) focus more on the organisational level from a more strategic perspective. Not surprisingly, there are themes (e.g. supplier relationships management) that have got both operational and strategic implications or other themes (e.g. people, skills and the purchasing/supply organisation) with implications for both the function and the organisation. Regardless, empirically driven models can be applied in each of these areas and can help with supply and purchasing decision making for the function or organisation from strategic to operational level. In Figure 1, a classification of these seven main themes is provided. The classification reflects our views and understanding (informed by years of interactions with P/SM scholars, managers and companies) of the discipline and it is not based on any objective and/or quantitative data analysis. 


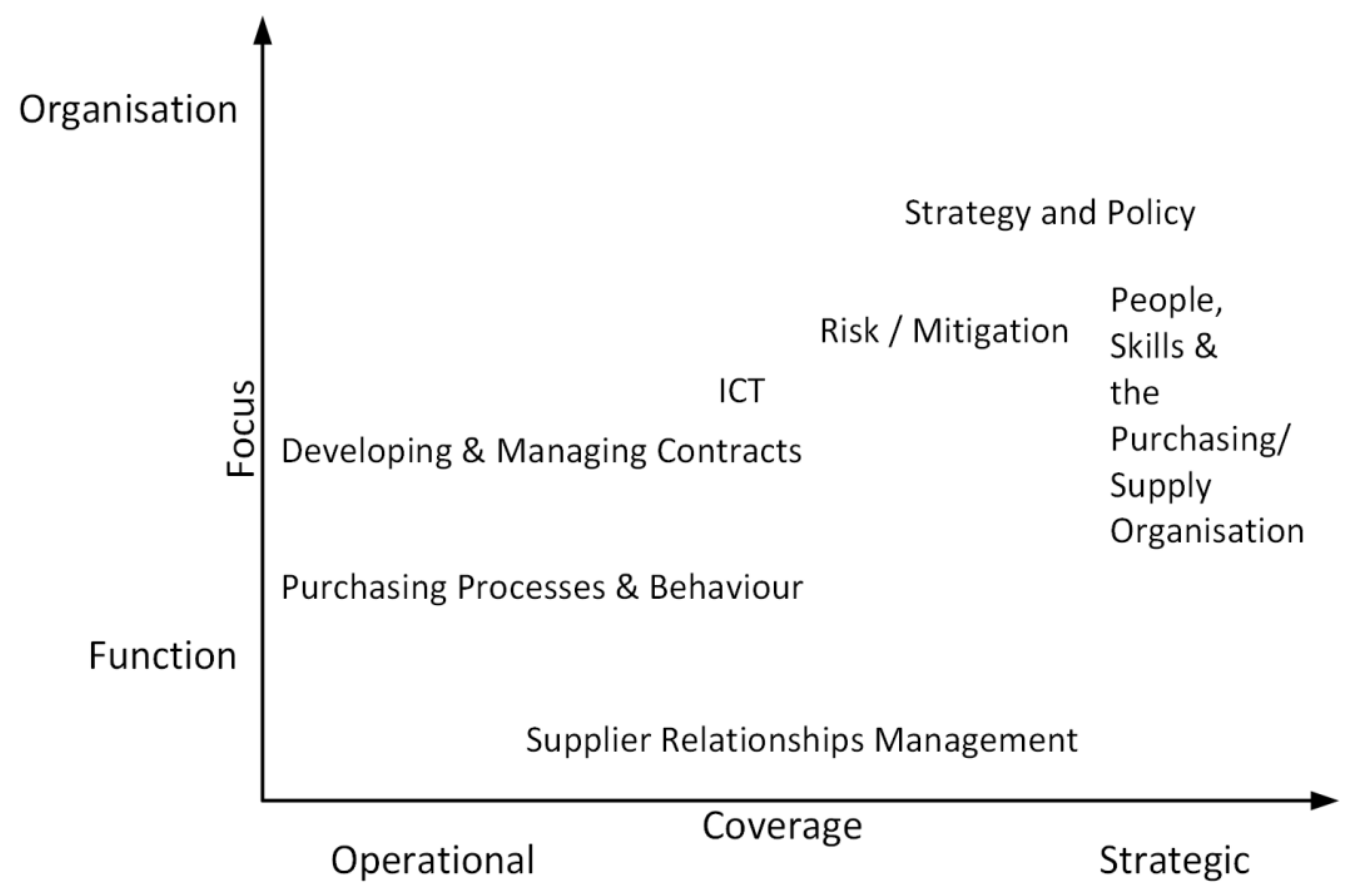

Figure 1. P/SM themes classification

\section{The Match/Mismatch}

Why do models make sense for P/SM research?

There are a number of opportunities to build and apply models in P/SM research. Additionally, combining an analytical model with empirical methods in a multi-method approach can create several advantages and has been called for in the SCM literature (Sanders \& Wagner, 2011; Cheng et al. 2012; Sanders et al. 2013, Choi et al. 2016). There are several reasons why P/SM researchers should consider empirically informed analytical models. For example, exploratory empirical methods, such as case studies and surveys, have the potential to generate relevant results from current business practice that can then be used to drive the design and inputs for a rigorous analytical model. In doing so, the experimental results of the model have the potential to be more externally valid and generalizable to practice, since the underlying tenants and parameters of the model are based more closely on actual real world data (Choi and Guide, 2012; Simchi Levi, 2014; Sodhi and Tang 2014).

Another approach may be utilised where results from an empirical study are then extrapolated or subjected to sensitivity analysis by either an optimisation model or simulation model. Such post-hoc analysis allows the research to further explore the relationships and sensitivity of the results in a controlled experimental setting where the analytical model is used to generate new results in addition to those gathered in the initial empirical stage (Choi et al. 2016). Additionally, when empirical data are difficult to collect or are not a sufficient sample size, analytical methods offer an option for generating additional data to ensure the rigor of the 
analysis. System simulations that use distribution-fitting techniques offer this ability, and they are one possible technique for applying a secondary analytic method after an empirical effort determines the initial range of inputs for variables (Evers and Wan, 2012).

The use of analytic methods can be used to extrapolate and forecast results for conditions that do not currently exist, and therefore they do not rely solely on the use of historical data as the input. Therefore, P/SM studies that combine an initial empirical study that creates a historical baseline for the phenomenon can be followed with an analytical study that extends the results based on anticipated changes in the parameters of the business environment. Such an approach has the potential to create a powerful predictive capability.

\section{What types of model have been used in P/SM research?}

A number of P/SM papers have recently combined analytic and empirical methods. However, the group of research papers offered below are not an exclusive list and have not been ranked in any way. Regardless, they do provide examples of the methodological approach recommended in this paper. First, Wagner et al. (2014), create an analytical model by combining real options valuation methods with a fuzzy goal programming optimisation method in order to schedule supply chain projects while accounting for relevant risks. This model is validated by applying empirical data to the model from a case study of twenty-one projects in a major Indian car manufacturer. In doing so, they show how the improved method accounts for risks not addressed by existing analytical methods.

Additionally, Huang and $\mathrm{Wu}$ (2016) combine portfolio theory and mathematical modelling for a steam-coal purchasing strategy and test the model with data from a Taiwanese power company. The real world data used in this optimisation model comprise price and quantity data for coal purchases in long-term and short-term spot market transactions. The authors find that the traditional models of minimising purchasing, transportation and holding costs do not capture the actual fluctuations in coal prices and an optimum purchasing strategy should also incorporate price risks.

Cui et al. (2015) study the impact of information sharing on forecast accuracy in the supply chain. Using interviews and empirical data from a major consumer packaged goods company, the results show that current theoretical models do not accurately follow the actual decision criteria used in practice. Using this knowledge, they are able to offer an improved analytical forecasting model that relaxes the limiting assumptions made in previous research. This work again shows how empirical evidence has the ability to improve analytical models and offer more relevant decision-making tools for practitioners. 
In addition, Gonzalez-Zapatero et al. (2016) use a descriptive model to explain the link between purchasing and marketing for new product development. Their research identifies essential components underlying purchasing and marketing integration including information sharing and the alignment of decisions, and they test the effect of different integration mechanisms on a sample of 141 Spanish industrial companies. Next, Sheu (2016) examines buyer behaviour in the procurement decision for recycled material with multi-sourcing. He uses a multi-method approach where the research hypotheses and analytical results from a multinomial logit model are validated using an empirical survey. Overall, we believe these examples of combining modelling with empirical methods in P/SM research have results with both increased generalisability and practical relevance due to the power of combining the methods.

\section{Gaps/opportunities/limitations}

In the following table an indicative list of topics is provided. The table is based on common P/SM themes, where different types of empirically driven models could be used. The table below should not be read as a well-defined research agenda, but more as an initial effort to demonstrate how and where modelling could be used in the P/SM field.

Table 1. Models that can be used in P/SM research

\begin{tabular}{|c|c|c|c|}
\hline \multirow{2}{*}{ P/SM themes } & \multicolumn{3}{|l|}{ Model types } \\
\hline & Descriptive & Predictive & Prescriptive \\
\hline $\begin{array}{l}\text { Supplier } \\
\text { Relationships } \\
\text { Management }\end{array}$ & $\begin{array}{l}\text { A model classifying } \\
\text { suppliers as critical, key, or } \\
\text { normal with respect to their } \\
\text { criticality to the company's } \\
\text { operations and criticality } \\
\text { configuration of the current } \\
\text { supply base (e.g. } 30 \% \\
\text { critical, } 20 \% \text { key, and } 50 \% \\
\text { normal suppliers). }\end{array}$ & $\begin{array}{l}\text { A forecasting model that } \\
\text { predicts the impact of a } \\
\text { disruption in the supply chain } \\
\text { based on a potential } \\
\text { operational incidents in } \\
\text { particular nodes of the supply } \\
\text { network. }\end{array}$ & $\begin{array}{l}\text { A model that finds the } \\
\text { optimal number of suppliers } \\
\text { needed to fulfill business } \\
\text { objectives (supplier } \\
\text { rationalisation) based on } \\
\text { cost constraints }\end{array}$ \\
\hline $\begin{array}{l}\text { Purchasing } \\
\text { Processes and } \\
\text { Behaviour }\end{array}$ & $\begin{array}{l}\text { A total landed cost model } \\
\text { considering the suppliers, } \\
\text { quantities ordered, and } \\
\text { logistics costs that shows the } \\
\text { current operational situation. }\end{array}$ & $\begin{array}{l}\text { Game theoretic models for } \\
\text { predicting the actions of } \\
\text { agents in a given } \\
\text { procurement scenario. }\end{array}$ & $\begin{array}{l}\text { A model that prescribes the } \\
\text { optimum amount to be } \\
\text { procured under quantity } \\
\text { discounts. }\end{array}$ \\
\hline $\begin{array}{l}\text { Developing and } \\
\text { Managing } \\
\text { Contracts }\end{array}$ & $\begin{array}{l}\text { Use longitudinal data on } \\
\text { contract terms and } \\
\text { management actions to } \\
\text { understand the real impact of } \\
\text { trust in B2B relationships. }\end{array}$ & $\begin{array}{l}\text { A predictive model that } \\
\text { estimates future performance } \\
\text { of the supplier based on } \\
\text { historical performance in } \\
\text { order to develop contract } \\
\text { incentives and penalties. }\end{array}$ & $\begin{array}{l}\text { A model that optimises the } \\
\text { contract parameters in order } \\
\text { for two transacting parties } \\
\text { (e.g. a buyer and a supplier) } \\
\text { to optimise their objective } \\
\text { functions (minimise cost, }\end{array}$ \\
\hline
\end{tabular}




\begin{tabular}{|c|c|c|c|}
\hline & & & maximise revenue or profit). \\
\hline $\begin{array}{l}\text { People, Skills and } \\
\text { the Purchasing/ } \\
\text { Supply } \\
\text { Organisation }\end{array}$ & $\begin{array}{l}\text { Understanding the process of } \\
\text { directing the behaviours and } \\
\text { decisions of procurement } \\
\text { activities within an } \\
\text { organisation via legislative, } \\
\text { executive and judicial } \\
\text { processes. }\end{array}$ & $\begin{array}{l}\text { A forecasting model that } \\
\text { predicts the number of } \\
\text { personnel and their required } \\
\text { skills. Outsourcing, mergers, } \\
\text { and operating start-ups could } \\
\text { create the need for such a } \\
\text { model. }\end{array}$ & $\begin{array}{l}\text { Work schedule and labour } \\
\text { utilisation models where } \\
\text { costs are minimised, and the } \\
\text { purchasing function } \\
\text { operates to effectively } \\
\text { complete sourcing tasks. }\end{array}$ \\
\hline $\begin{array}{l}\text { Strategy and } \\
\text { Policy }\end{array}$ & $\begin{array}{l}\text { Procurement or sourcing } \\
\text { seeks to find, evaluate and } \\
\text { engage suppliers to achieve } \\
\text { cost savings and best value } \\
\text { for goods and services, } \\
\text { which can be done through a } \\
\text { tender process. This process } \\
\text { can be described in a model } \\
\text { where factors such as } \\
\text { reliability, quality, flexibility } \\
\text { and capacity are considered } \\
\text { in the tendering process } \\
\text { alongside price. }\end{array}$ & $\begin{array}{l}\text { A forecasting or regression } \\
\text { model that predicts the } \\
\text { impact of a policy change on } \\
\text { current or on-going supply } \\
\text { operations. For example, } \\
\text { taxes, tariffs or other } \\
\text { restrictive policy may impact } \\
\text { the quantity and costs of } \\
\text { procured materials. }\end{array}$ & $\begin{array}{l}\text { Network optimisation } \\
\text { models can be built that } \\
\text { analyse the selection and } \\
\text { location of suppliers where } \\
\text { the right mix of suppliers is } \\
\text { optimised. These models } \\
\text { can also be used to } \\
\text { minimize supply side risks. }\end{array}$ \\
\hline$I C T$ & $\begin{array}{l}\text { A model that describes the } \\
\text { performance of e-auctions } \\
\text { based on the demographics } \\
\text { of customers, length of the } \\
\text { auctions, size of individual } \\
\text { purchases, etc. }\end{array}$ & $\begin{array}{l}\text { Using practical data from e- } \\
\text { Sourcing / e-Procurement, e- } \\
\text { Auctions/Reverse Auctions } \\
\text { in systems models to } \\
\text { understand and predict actual } \\
\text { and future purchasing } \\
\text { behaviour in response to } \\
\text { various signals (e.g. price } \\
\text { changes). }\end{array}$ & $\begin{array}{l}\text { Building algorithms that } \\
\text { optimize the bidding and } \\
\text { acceptance processes for e- } \\
\text { procurement or e-auctions. } \\
\text { Such models could be } \\
\text { driven by surveys of } \\
\text { procurement personnel to } \\
\text { learn heuristics and set } \\
\text { parameters for the model. }\end{array}$ \\
\hline Risk / Mitigation & $\begin{array}{l}\text { A model that quantifies the } \\
\text { risks involved with supply } \\
\text { chain operations based on a } \\
\text { combination of current } \\
\text { supplier's locations (e.g. } \\
\text { macro level country risk) } \\
\text { and financial risk of the } \\
\text { suppliers (e.g. micro level } \\
\text { company risk). }\end{array}$ & $\begin{array}{l}\text { A model estimating the time } \\
\text { for supply operations to } \\
\text { recover from possible } \\
\text { disruptions to specific nodes } \\
\text { in the supply chain based on } \\
\text { empirical data from historical } \\
\text { disruption events. }\end{array}$ & $\begin{array}{l}\text { A network or location } \\
\text { model prescribing which } \\
\text { suppliers' nodes in the } \\
\text { supply chain need to be } \\
\text { strengthened for higher } \\
\text { resilience. }\end{array}$ \\
\hline
\end{tabular}

\section{Conclusions}

There are many opportunities for using descriptive, predictive and prescriptive modelling approaches in P/SM research. In today's research, studies often conduct tests that are only incremental changes to previous research and may not be based on any observed phenomenon in the business world. Therefore, empirical methods are needed to identify the model parameters and drive the experimental agenda for predictive and prescriptive models. One way to do this is to use a multi-method approach where an empirical case study or survey is used to gain insight into practice, and the results are used to frame the testing in a model that follows. Such empirically driven models have the potential to make significant contributions in P/SM research and a number of indicative research areas are provided in Table 1. Also in the context of the 
P/SM themes classification presented in Figure 1 and in conjunction with the indicative research areas proposed in Table 1, future P/SM research needs to explore the value of modelling not just at the functional or operational level, but also at the organisation and strategic level respectively.

While using empirical results to inform and improve models has advantages, there are also drawbacks. For example, Reidl et al. (2014) analysed 988 papers with results from covariance-based structural equation models in the supply chain domain, and they found $32 \%$ of the papers lacked adequate statistical power, which directly affects the meaningfulness of the conclusions. Awareness around statistical power is an integral part of rigour in the research process, and the validity results of any modelling effort will need to include a rigorous consideration of statistical power. Additionally, multi-method research offers the ability to ground or test the findings from a single study, but it can also create other issues.

Petersen and Autry (2014) state that it is often difficult to publish multi-method research in supply chain management due to reviewers not being familiar or comfortable with the literature from other disciplines or the common methods used outside their own field. This limitation could be a problem when combining an analytic model and empirical methods in a purchasing setting and readers should consider ways to overcome this issue. Additional limitations and difficulties of publishing multi-method research are also pointed out in a paper by Choi et al. (2016). These authors recommend that reviewers and authors in the future should consider the rigor and contributions of the combined methods and not criticize each part of the research as if it is an independent study. In the meantime, authors who choose to conduct purchasing and supply management research using combined modelling and empirical methods need to understand that they may encounter resistance and need to provide a convincing argument of the value, practical relevance and generalizability of the multi-method approach in addition to ensuring the rigor of multiple methods.

\section{References}

Gonzalez-Zapatero, C., Gonzalez-Benito, J. and Lannelongue, G. (2016). Antecedents of functional integration during new product development: The purchasing-marketing link, Industrial Marketing Management, 52: 47-59.

Cheng, T. C., Choi, T. M. and Zhao. X. (2012). Special issue of production and operations management: Multi-methodological research in production and operations management. Production \& Operations Management 21(6): 1059-1478.

Choi, T. M., Cheng, T.C.E. and Zhao X. (2016). Multi-Methodological Research in Operations Management. Production \& Operations Management 25(3): 379-389.

Choi, T. M., Guide, V. and Daniel R. (2012). Updates from the Editors. Journal of Operations Management, 30, 507-508. 
Cui, R., G. Allon, A. Bassamboo, J. and Van Mieghem, A. (2015). Information sharing in supply chains: An empirical and theoretical valuation. Management Science, 61(11): 2803-2824.

Dong, M. C., Z. Liu, Y. Yu, J. H. Zheng. (2015). Opportunism in distribution networks: The role of network embeddedness and dependence. Production \& Operations Management, 24(10): $1657-1670$.

Evers, P. T. and Xiang, W. (2012). Systems analysis using simulation. Journal of Business Logistics, 33(2), 80-89.

Govindan, K., Kaliyan, M., Kannan, D., and Haq, A. N. (2014). Barriers analysis for green supply chain management implementation in Indian industries using analytic hierarchy process. International Journal of Production Economics, 147, 555-568.

Huang, Y.H., and Wu, J.H. (2016). A portfolio theory based optimization model for steam coal purchasing strategy: A case study of Taiwan Power Company. Journal of Purchasing and Supply Management 22(2): 131-140.

Marzouk, M., Shinnawy, N. E., Moselhi, O. and El-Said, M. (2013). Measuring sensitivity of procurement decisions using superiority and inferiority ranking. International Journal of Information Technology \& Decision Making, 12(03): 395-423.

Niranjan, T. T., Wagner, S. M. and Bode, C. (2011). An Alternative Theoretical Explanation and Empirical Insights into Overordering Behavior in Supply Chains. Decision Sciences 42 (4): 859888.

Petersen, K. J. and Autry, C.A. (2014). Supply Chain Management at the Crossroads: Divergent Views, Potential Impacts, and Suggested Paths Forward, Journal of Business Logistics 35(1): 3643.

Riedl, D. F., Kaufmann, L. and Gaeckler, J. (2014). Statistical power of structural equation models in SCM research. Journal of Purchasing and Supply Management 20(3): 208-212.

Sanders, N. R., and Wagner. S. M. (2011). Multidisciplinary and Multimethod Research for Addressing Contemporary Supply Chain Challenges. Journal of Business Logistics 32 (4): 317323.

Sanders, N. R., Zacharia, Z. G. and Fugate, B. S. (2013). The Interdisciplinary Future of Supply Chain Management Research. Decision Sciences 44 (3): 413-429.

Sheu, J. B. (2016). Buyer behavior in quality-dominated multi-sourcing recyclable-material procurement of green supply chains. Production \& Operations Management, 25(3): 477-497

Simchi-Levi, D. (2014). OM research: From problem-driven to data driven research. Manufacturing Services Operations Management 16(1): 2-10.

Sivapornpunlerd, N., and Setamanit, S. O. (2014). Supplier Performance Evaluation Using Analytical Hierarchy Process: A Case Study of Thai Offshore Oil \& Gas Exploration and Production Company. Journal of Business and Behavior Sciences, 26(3), 63. 
Sodhi, M. S. and Tang, C. S. (2014). Guiding the next generation of doctoral students. International Journal of Production Economics, 150: 28-36.

Wagner, S. M., Padhi, S. S. and Zanger, I. (2014). A real option-based supply chain project evaluation and scheduling method. International Journal of Production Research, 52(12), 37253743. 